\title{
Comparison of inbreeding and outbreeding in hermaphroditic Arianta arbustorum (L.) (land snail)
}

\author{
XIAOFENG CHEN \\ Institute of Zoology, University of Basel, Rheinsprung 9, CH-4051 Basel, Switzerland
}

\begin{abstract}
Inbreeding depression was studied in the outcrossing hermaphroditic land snail Arianta arbustorum, by comparing the reproductive performance of full-sib pairs (inbreeding) and pairs of unrelated individuals (outbreeding). Fecundity (number of eggs laid) was not found to differ significantly between inbreeding and outbreeding pairs under laboratory conditions, but fertility (the proportion of eggs that hatched) and the number of hatchlings produced by inbreeding pairs were significantly lower than those of outbreeding pairs. Estimates of reduction in the fertility of eggs $(0.37)$ and in the number of hatchlings produced $(0.56)$ suggested significant inbreeding depression in full-sib crosses. Inbred offspring reared in the garden had a higher mortality than outbred offspring reared in the same environment, with an inbreeding depression of 0.30 in the first year after hatching; but no significant difference was found when offspring from both groups were kept in the laboratory. The results support the hypothesis that cross-fertilization in simultaneous hermaphrodites is maintained by strong inbreeding depression.
\end{abstract}

Keywords: Arianta arbustorum, full-sib mating, hermaphrodite, inbreeding depression, land snail, outcrossing.

\section{Introduction}

The effects of inbreeding had been known well before Darwin and, since the development of Mendelian genetics, the causative mechanism has been known, at least in principle (Crow \& Kimura, 1970; Wright, 1977). Although the mating system and genetic structure of populations are often assumed to be strongly influenced by inbreeding depression, its magnitude and evolutionary consequences remain obscure in most animals and plants (Charlesworth \& Charlesworth, 1987). For simultaneous hermaphrodites, inbreeding depression is regarded as the most important selective force acting against self-fertilization (selfing), and maintaining cross-fertilization (outcrossing) (Ghiselin, 1969, 1974; Maynard Smith, 1978; Lloyd, 1979; Lande \& Schemske, 1985; Charlesworth \& Charlesworth, 1987). If inbreeding depression is low or absent, mutations causing selfing should spread in a population of cross-fertilizing hermaphrodites. Generally, inbreeding depression under selfing should be greater than 0.5 to maintain cross-fertilization (Maynard Smith, 1978;

Correspondence: Institute of Zoology, Academia Sinica, 19 ZhongGuan-Cun Lu, Beijing 100080, China.
Charlesworth \& Charlesworth, 1990). On the other hand, inbreeding depression is not fixed in a population; it could be influenced by the mating system or mating history, which may evolve in association. Hence, high inbreeding depression is expected in cross-fertilizing populations and relatively low inbreeding depression in self-fertilizing populations (Maynard Smith, 1978; Wells, 1979; Lande \& Schemske, 1985; Charlesworth \& Charlesworth, 1987).

Although most studies on inbreeding depression and self-fertilization have used plants, molluscs provide a unique group of animals whose breeding systems are almost as diverse (Bell, 1982; Geraerts \& Joosse, 1984; Tompa, 1984). Among molluscs, pulmonate snails are almost all hermaphrodites (Duncan, 1975) and the extent of selfing varies considerably. Some species reproduce predominantly through cross-fertilization, others facultatively self-fertilize but persistently selfing species also exist (Geraerts \& Joosse, 1984; Tompa, 1984). Research on the inbreeding depression of hermaphroditic snails has been carried out in species that can reproduce by self-fertilization. The reproductive success of selfed and outcrossed individuals has been compared in the freshwater snails Bulinus globosus (Jarne et al., 1991), Lymnaea columella and 
L. stagnalis (Cain, 1956), L. peregra (Jarne \& Delay, 1990) and in land snails Punctum pygmaeum (Baur, 1989), Rumina decollata (Selander et al., 1974) and Triodopsis albolabris (McCracken \& Brussard, 1980). The possible effects of inbreeding in outcrossing species have not been reported, except in Helix aspersa (Albuquerque de Matos \& Serra, 1984). Furthermore, the fitness reduction of selfing compared with outcrossing may not be an adequate estimate of inbreeding depression because self-compatibility barriers, inbreeding avoidance behaviour and other factors could also greatly influence the reproductive success of selfers (Charlesworth \& Charlesworth, 1987; Jarne et al., 1991). To obtain a better estimate of inbreeding depression, inbreeding other than that produced by selfing should be studied for self-compatible species. Inbreeding depression should also be measured by crosses between relatives in self-incompatible species to test its potential effect on the evolutionary maintenance of cross-fertilization.

Arianta arbustorum is a common helicid land snail of northwestern and central Europe (Kerney \& Cameron, 1979), that typically outcrosses (Lang, 1904; Frömming, 1954). A. arbustorum was long believed to be self-incompatible but occasional selfing with attendant low reproductive success has been observed (Chen, 1993b). In this article, data on an experimental test of inbreeding depression in A. arbustorum are presented. The reproductive success, measured by fecundity (number of eggs produced), fertility (hatching success of eggs), number of hatchlings produced and offspring survival and growth was compared between full-sib pairs and non-related pairs.

\section{Materials and methods}

Sub-adult snails were collected from a sub-alpine forest near Gurnigel in Switzerland $\left(46^{\circ} 44^{\prime} \mathrm{N}, 7^{\circ} 27^{\prime} \mathrm{E}\right.$; altitude $1430 \mathrm{~m}$ ) on 3 May 1990 . They were collected at four sites situated 500-1000 m apart from each other. Individuals from different sites were, presumably, not closely related to each other. The snails were kept in isolation under laboratory conditions until they reached sexual maturity, as indicated by a hard reflected lip at the shell aperture. The virgin adults ( $\mathrm{P}$ snails) were allowed to copulate once with a mate from the same site. Their offspring $\left(F_{1}\right.$ snails $)$ were reared under laboratory conditions until they reached sexual maturity (after 1 or 2 years). The $F_{1}$ adults were then paired in two ways: (i) in the inbreeding group, full-sib snails (from the same egg batch) were paired ( 21 pairs); and (ii) in the outbreeding group, unrelated snails (derived from different sites) were paired (18 pairs). The reproductive performance of snails in these two groups was recorded for one reproductive season (lasting 4 months). Eggs were collected every seventh day and incubated on moist tissue paper at $19^{\circ} \mathrm{C}$. Hatchlings were counted and removed each day to prevent egg cannibalism (Baur \& Baur, 1986). Survival rates of inbred and outbred offspring were observed in two environments in 1991. Fifteen hatchlings ( $F_{2}$ snails $)$ from each pair of snails were reared in the laboratory for 100 days, and another 15 were reared in the garden for 1 year except during the hibernation period (December to March, see below). In the laboratory, all snails were maintained in environmental chambers at a constant temperature of $19^{\circ} \mathrm{C}$ with a $18 \mathrm{~L} / 6 \mathrm{D}$ light cycle. In the garden (outside the Zoological Institute, University of Basel), the snails were kept in a shaded place under natural conditions of temperature and light.

Paired snails were kept in boxes measuring $10 \times 14 \times 7 \mathrm{~cm}$, sub-adults and virgin adults were kept in beakers measuring $6 \mathrm{~cm}$ in diameter and $8 \mathrm{~cm}$ in height. Hatchlings younger than 2 weeks were reared in dishes measuring $7 \mathrm{~cm}$ in diameter and $2 \mathrm{~cm}$ in height. Juvenile snails less than 4 months old were reared in beakers measuring $7 \mathrm{~cm}$ in diameter and $5 \mathrm{~cm}$ in height, with less than four individuals per box. The bottom of the containers was covered with moist soil mixed with calcium carbonate. Fresh lettuce was provided as food ad libitum. The containers were cleaned at least twice per week. In winter, all snails were kept individually in a cool dark room at $4^{\circ} \mathrm{C}$ with no food provided.

Statistical analyses were performed using SAS programmes (SAS Institute Inc., 1989).

\section{Results}

Some snail pairs did not reproduce successfully. All the snail pairs laid eggs but 14 of the 21 inbreeding pairs and nine of the 18 outbreeding pairs produced no hatchlings. One outcrossing pair laid 64 eggs but only one of the eggs hatched. The other snail pairs produced from 15 to 272 hatchlings. The snail pair that produced only one hatchling, and the 23 snail pairs that produced no hatchlings were regarded as non-reproductive (see below and Discussion). These non-reproductive snail pairs produced slightly fewer clutches than the reproductive pairs (mean \pm S.E. $12.0 \pm 1.1$ vs. $15.4 \pm 1.1 ; t$-test: $t=2.01$, d.f. $=37, P=0.05$ ) but with much smaller clutches (mean \pm S.E. $4.27 \pm 0.33$ vs. $18.53 \pm 2.52$; $t$-test, for unequal variances: $t=5.6$, d.f. $=14.5, P<0.001)$ and thus laid significantly fewer eggs (mean \pm S.E. $54.7 \pm 7.4$ vs. $272.2 \pm 34.5$; $t$-test, for unequal variances: $t=6.17$, d.f. $=15.3, P<0.001$ ). All of the eggs laid by these non-reproductive snails that 
failed to hatch showed no embryo development but a considerable part (21.1 per cent) of the unhatched eggs laid by the reproductive snails clearly showed an embryo. The proportion of snail pairs that failed to reproduce successfully did not differ significantly between the inbreeding group and the outbreeding group (14 of $21,66.7$ per cent vs. 10 of $18,55.6$ per cent; chi-squared $=0.51$, d.f. $=1, P>0.40$ ).

\section{Reproduction in inbreeding and outbreeding snails}

To compare the fecundity and fertility of inbreeding and outbreeding snail pairs, only data from the snail pairs that reproduced successfully were considered. The number of clutches produced and the clutch sizes did not differ significantly between the inbreeding and outbreeding snail pairs (Table 1). Thus, the number of eggs laid (fecundity) did not differ significantly between the two groups either $(t$-test, $P=0.20$; Table 1$)$. The hatching success of eggs (the proportion of eggs that hatched) from outbreeding snails was significantly higher than that from inbreeding snail pairs ( $t$-test, $P=0.02$; Table 1). Consequently, the outbreeding pairs produced significantly more hatchlings than inbreeding pairs ( $t$-test, $P=0.04$; Table 1$)$. The reproductive snails from both breeding groups laid some eggs that showed visible embryo development but failed to hatch. The number of these fertilized but unhatched eggs did not differ significantly between the inbreeding and outbreeding groups (Table 1).

\section{Survival and growth of inbred and outbred offspring}

The survival curves of offspring from inbreeding and outbreeding snails are shown in Fig. 1. During the first 100 days in the garden, offspring from inbreeding pairs had significantly higher mortality than offspring from outbreeding pairs ( $\log$ rank test, chi-squared $=7.5$, d.f. $=1, P<0.01$ ); this difference was still apparent after a year $(\log$ rank test, chi-squared $=5.4$, d.f. $=1$, $P=0.02$ ). In the laboratory, however, the two groups did not differ significantly in offspring survival within the first 100 days after hatching (log rank test, chisquared $=1.8$, d.f. $=1, P=0.18$ ). The offspring hatched at different dates during the season and thus may have experienced different environmental conditions in the garden (mean \pm S.E. of the date at hatching for inbred offspring reared in garden: $151.9 \pm 4.2$; for outbred offspring reared in garden: $144.5 \pm 11.0$; the day is numbered from the first day of the year). However, offspring survival is not associated with the date of hatching (log rank test for association with covariates, within 100 days: chi-squared $=1.9$, d.f. $=1, P>0.10$; within 1 year: chi-squared $=1.9$, d.f. $=1, P>0.10$ ).

Inbred offspring raised in the garden were significantly smaller than outbred offspring in terms of the shell breadth at the age of one year $(P<0.05$; Table 2$)$. The shell size did not differ significantly between families within the breeding groups $(P>0.05$; Table 2$)$. The association between the date of hatching and shell size was not significant $(P>0.10$; Table 2$)$.

\section{Estimate of inbreeding depression}

Inbreeding depression is measured as the proportional decrement in the mean phenotypic values caused by inbreeding (Falconer, 1981):

$d=1-M_{\mathrm{ib}} / M_{\mathrm{ob}}$,

where $M_{\mathrm{ib}}$ and $M_{\mathrm{ob}}$ are the mean phenotypic values in the inbred and outbred (control) groups.

Based on the difference between the breeding groups in hatching success of the eggs, the inbreeding depression for full-sib mating is:

$d=1-0.304 / 0.485=0.373$.

Based on the difference in the number of hatchlings produced, the inbreeding depression is:

Table 1 Comparison of reproductive performance between inbreeding (full-sib crosses) and outbreeding pairs of Arianta arbustorum

\begin{tabular}{lccc}
\hline & $\begin{array}{l}\text { Inbreeding } \\
\text { pairs }(n=7)\end{array}$ & $\begin{array}{l}\text { Outbreeding } \\
\text { pairs }(n=8)\end{array}$ & $t$ value $(P)$ \\
\hline Number of clutches & $13.6 \pm 1.4$ & $17.0 \pm 1.6$ & $1.57(0.14)$ \\
Clutch size & $17.2 \pm 3.2$ & $19.7 \pm 3.9$ & $0.50(0.60)$ \\
Number of eggs & $244.6 \pm 44.5$ & $313.9 \pm 49.3$ & $1.33(0.20)$ \\
Hatching success of eggs & $0.304 \pm 0.028$ & $0.485 \pm 0.056$ & $2.75(0.02)$ \\
Number of hatchlings & $73.0 \pm 19.2$ & $164.6 \pm 34.5$ & $2.22(0.04)$ \\
Number of dead embryos & $22.14 \pm 8.94$ & $40.00 \pm 10.73$ & $1.25(0.23)$ \\
\hline
\end{tabular}

Values are mean \pm standard errors. 


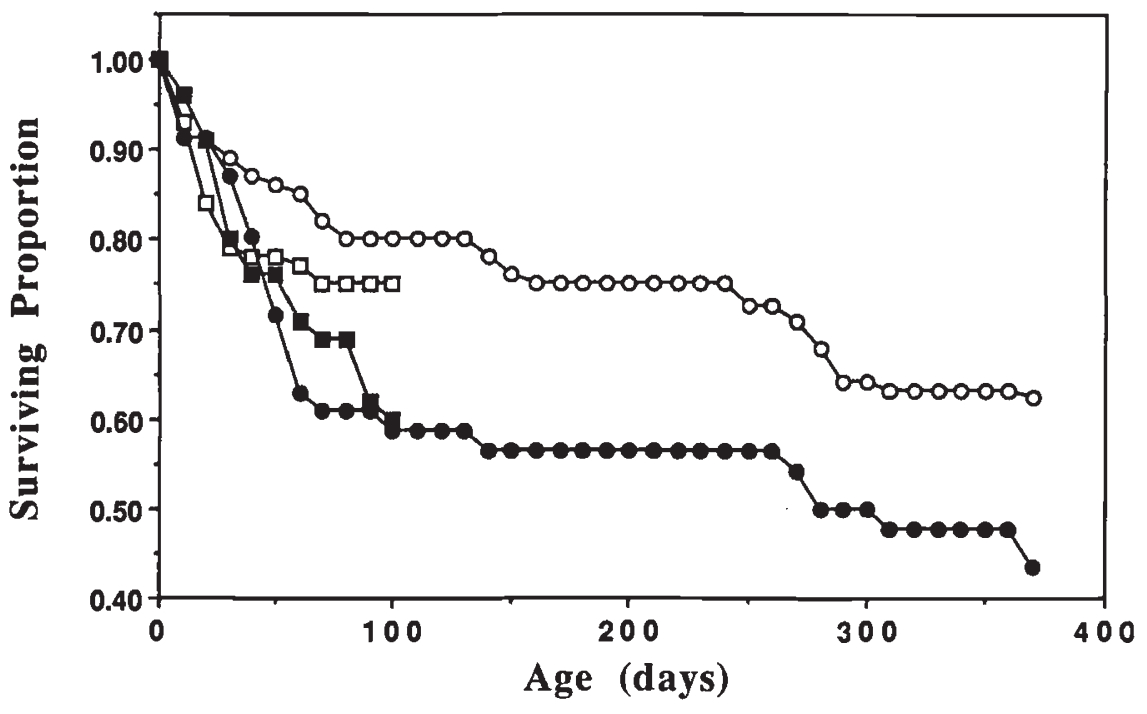

Fig. 1 Survival curve of inbred and outbred offspring raised in laboratory and garden environments. (O) Outbred offspring in garden, $N=90 ;(\square)$ outbred offspring in laboratory, $N=90 ;(\boldsymbol{\square})$ inbred offspring in laboratory, $N=45$; (•) inbred offspring in garden, $N=45$.
Table 2 Shell breadth of inbred and outbred offspring reared in the garden at the age of one year, with an analysis of covariance

\begin{tabular}{lllll}
\hline & \multicolumn{2}{c}{ Inbred offspring } & \multicolumn{2}{c}{ Outbred offspring } \\
\cline { 2 - 5 } Mean \pm s.d. $(\mathrm{mm})$ & $12.0 \pm 3.4$ & & \multicolumn{2}{c}{$15.0 \pm 2.9$} \\
\hline ANCOVA & Source & d.f. & Mean square & $F$ value \\
\cline { 2 - 5 } & Breeding & 1 & 3894.5 & $4.5^{*}$ \\
& Family (breeding) & 8 & 1325.7 & $1.52 \mathrm{~ns}$ \\
& Hatch date & 1 & 868.4 & $0.99 \mathrm{~ns}$ \\
& Error & 69 & 874.8 & \\
\hline
\end{tabular}

*: $P<0.05$; ns: $P>0.05$.

$d=1-73.0 / 164.6=0.557$.

In the garden, 43.5 per cent of the inbred offspring survived the first year in contrast to 62.3 per cent of the outbred offspring. The inbreeding depression based on survival during that stage is:

$d=1-0.435 / 0.623=0.302$.

\section{Discussion}

In the present study, the effects of inbreeding depression in full-sib crosses was found in hatching success, number of hatchlings produced and offspring survival and growth. In a related outcrossing land snail, Helix aspersa, Albuquerque de Matos \& Serra (1984) found that crosses between relatives caused infertility and decreased number of offspring but the magnitude of inbreeding depression was not measured. No other studies on inbreeding effects in outcrossing land snails were reported, despite its importance for explaining the maintenance of cross-fertilization.

Reduced reproductive success caused by selfing, relative to outcrossed individuals, has been reported in some fresh water and land snails, such as Bulinus globosus (Jarne et al., 1991), Lymnaea peregra (Jarne \& Delay, 1990), Triodopsis albolaris (McCracken \& Brussard, 1980), as well as $A$. arbustorum (Chen, 1993b). The present data provided an opportunity for analysing the cause of fitness reduction in selfed individuals of A. arbustorum. Theoretically, inbreeding depression is approximately proportional to the coefficient of inbreeding (Falconer, 1981). A value of 0.37 for inbreeding depression based on fertility of full-sib crosses (inbreeding coefficient: 0.25 ), suggests that the corresponding inbreeding depression of selfing (inbreeding coefficient: 0.5 ) should approximate to 0.74 . However, using animals from the same population to study the effects of self-fertilization and crossfertilization, a 90-100 per cent fertility reduction in selfed vs. outcrossed individuals was observed (Chen, 1993a, b). Furthermore, in contrast to the present study, there was a greater than 80 per cent reduction in clutch size and egg number laid by selfed relative to outcrossed snails. This suggests that the fitness reduction imposed by selfing compared with outcrossing may also come from self-compatibility barriers and inbreeding avoidance behaviour in addition to inbreeding depression.

Individuals from outcrossing populations are expected to have substantial inbreeding depression when inbred and this would select for self-incompatibility mechanisms or inbreeding avoidance behaviour, 
thus cross-fertilization could be maintained (Maynard Smith, 1978; Charlesworth \& Charlesworth, 1987). On the other hand, selfing can purge deleterious alleles and reduce inbreeding depression. This combined with ecological and resource allocation advantages could maintain self-fertilization, leading to an association between selfing and low inbreeding depression. Such interactions between mating system and inbreeding depressions are at least partly responsible for the observed bimodal distribution of selfing rates in plants (Lande \& Schemske, 1985; Schemske \& Lande, 1985). Hermaphroditic snails may have the same pattern as well. Several theoretical analyses predict that outcrossing must be maintained by strong inbreeding depression (generally greater than 0.50 for selfing) in simultaneous hermaphrodites, although many other factors may also be a significant influence (Maynard Smith, 1978, 1989; Charlesworth et al., 1990). The present data supported that prediction.

Explanations as to why some snail pairs did not reproduce successfully in the present experiment should consider reasons other than mating system, as the ratio of reproductive vs. non-reproductive pairs did not differ significantly between the inbreeding and outbreeding groups. The snail pair that produced one hatchling was classified as non-reproductive, for at least one of the two snails did not reproduce, and because unmated individuals of $A$. arbustorum are able to lay fertile eggs occasionally (although mostly in the second and third years after maturity, it has also been found in the first year; Chen, 1993b). The nonreproductive snail pairs showed a similar pattern of egg laying as the snails prevented from mating; the fewer eggs laid were a result of smaller clutches (Chen, 1993a, b). As the inbred and outbred snails $\left(F_{1}\right.$ snails $)$ were raised entirely under laboratory conditions, it is possible that unknown laboratory effects prevented some snails from copulating and reproducing. It has been reported that in captivity, land snails generally copulate less readily than freshwater snails (Duncan, 1975). Infertility in paired snails, presumably arisen from incompatibility or sterility, has been observed in Helix aspersa (Albuquerque de Matos \& Serra, 1984). Mating experiments in A. arbustorum have shown that snails raised in the laboratory were less ready to copulate than snails from the field (X. Chen, unpublished data).

Inbred offspring raised in the garden had a lower survival rate than outcrossed offspring but the difference is not significant in the laboratory environment. This suggests that ecological conditions could greatly influence the expression of inbreeding effects. Interaction between genetic and ecological factors should be considered in studying the evolution of a breeding system.

\section{Acknowledgements}

Comments from B. Baur, T. Kawecki, C. Müller, R. Nager, V. Perrot, N. Rank, S. C. Stearns and two anonymous referees greatly improved the manuscript. Financial support was received from the Swiss National Science Foundation (grant number 31-26258.89 to B. Baur).

\section{References}

Albuquerque DE matos, R. M. AND SERrA, J. A. 1984. Taxonomic polymorphism and intrinsic factors in Helix aspersa. Broteria-Genetica, Lisboa V (LXXX), 181-220.

BAUR, B. 1989. Growth and reproduction of the minute land snail Punctum pygmaeum (Draparnaud). J. Moll. Stud., 55, 383-387.

BAUR, B. AND BAUR, A. 1986. Proximate factors influencing egg cannibalism in the land snail Arianta arbustorum (Pulmonata, Helicidae). Oecologia (Berl.), 70, 283-287.

BELL, G. 1982. The Masterpiece of Nature: the Evolution and Genetics of Sexuality. University of California Press, Berkeley.

CAIN, G. L. 1956. Studies on cross-fertilization and self-fertilization in Lymnaea stagnalis appressa Say. Biol. Bull., 111, 45-52.

CHARLESWORTH, D. AND CHARLESWORTH, B. 1987. Inbreeding depression and its evolutionary consequences. Ann. Rev. Ecol. Syst., 18, 237-268.

CHARLESWORTH, D. AND CHARLESWORTH, B. 1990. Inbreeding depression with heterozygote advantage and its effect on selection for modifiers changing the outcrossing rate. Evolution, 44, 870-888.

CHARLESWORTH, D., MORGAN, M. T. AND CHARLESWORTH, B. 1990. Inbreeding depression, genetic load, and the evolution of outcrossing rate in a multilocus system with no linkage. Evolution, 44, 1468-1489.

CHEN, X. 1993a. On Reproductive Strategies in Hermaphroditic Land Snails. Ph.D. Thesis, University of Basel, Switzerland.

CHEN, X. 1993b. Self-fertilization and cross-fertilization in the land snail Arianta arbustorum (Mollusca, Pulmonata: Helicidae). J. Zool. (London) (in press).

Crow, J. F. AND KIMURA, M. 1970. An Introduction to Population Genetics Theory. Harper \& Row, New York.

DUNCAN, C. J. 1975. Reproduction. In: Fretter, V. and Peake, J. (eds), Pulmonates, vol. 1. pp. 309-365. Academic Press, New York.

FALCONER, D. S. 1981. Introduction to Quantitative Genetics, 2nd edn, Longman, London.

FROMMING, E. 1954. Biologie der mitteleuropäischen Landgastropoden. Duncker \& Humblot, Berlin.

GERAERTS, W. P. M. AND JOOSSE, J. 1984. Freshwater snails (Basommatophora). In: Tompa, A. S., Verdonk, N. H. \& 
van den Biggelaar, J. A. M. (eds), The Mollusca, vol. 7: Reproduction. Academic Press, New York, pp. 141-207.

GHISELIN, M. T. 1969. The evolution of hermaphroditism among animals. Q. Rev. Biol., 44, 189-208.

GHISELIN, M. T. 1974. The Economy of Nature and the Evolution of Sex. University of California Press, Berkeley.

JARNE, P. AND DELAY, B. 1990. Inbreeding depression and selffertilization in Lymnaea peregra (Gastropoda: Pulmonata). Heredity, 64, 169-175.

JARNE, P., FINOT, L., DELAY, B. AND THALER, L. 1991. Self-fertilization versus cross-fertilization in the hermaphroditic freshwater snail Bulinus globosus. Evolution, 45, 1136-1146.

KERNEY, M. P. AND CAMERON, R. A. D. 1979. A Field Guide to the Land Snails in Britain and North-West Europe. Collins, London.

LANG, A. 1904. Ueber Vorversuche zu Untersuchungen über die Varietätenbildung von Helix hortensis Müller und Helix nemoralis L. Festschrift zum siebzigsten Geburtstage von Ernst Haeckel. Verlag von Gustav Fischer, Jena.

LANDE, R. AND SCHEMSKE, D. W. 1985. The evolution of selffertilization and inbreeding depression in plants. I. Genetic models. Evolution, 39, 24-40.

LLOYD, D. G. 1979. Some reproductive factors affecting the selection of self-fertilization in plants. Am. Nat., 113, 67-79.
MCCRACKEN, G. F. AND BRUSSARD, P. F. 1980. Self-fertilization in the white-lipped land snail Triodopsis albolabris. Biol. $J$. Linn. Soc., 14, 429-434.

MAYNARD SMITH, J. 1978. The Evolution of Sex. Cambridge University Press, Cambridge.

MAYNARD SMITH, J. 1989. Evolutionary Genetics. Oxford University Press, Oxford.

SAS INSTITUTE INC. 1989. SAS/STAT User's Guide, Version 6, 4th edn. SAS Institute Inc., Cary, NC.

SCHEMSKE, D. W. AND LANDE, R. 1985. The evolution of selffertilization and inbreeding depression in plants. II. Empirical observations. Evolution, 39, 41-52.

SELANDER, R. K., KAUFMAN, D. W. AND RALIN, R. S. 1974. Self-fertilization in the terrestrial snail Rumina decollata. The Veliger, 16, 265-270.

TOMPA, A. S. 1984. Land snails (Stylommatophora). In: Tompa, A. S., Verdonk, N. H. and van den Biggelaar, J. A. M. (eds), The Mollusca, vol. 7, Reproduction. Academic Press, New York, pp. 48-141.

WELLS, H. 1979. Self-fertilization: advantageous or deleterious? Evolution, 33, 252-255.

WRJGHT, s. 1977. Evolution and the Genetics of Populations, vol. 3, Experimental Results and Evolutionary Deductions. University of Chicago Press, Chicago. 